\title{
KAJIAN DRAINASE RAMAH LINGKUNGAN DENGAN MEMPERHITUNGKAN SUMUR RESAPANUNTUK ANTISIPASI BANJIR PADA PERUMAHAN AURA BIMANTARA KAMPUNG BUGIS KECAMATAN ALAM BARAJO
}

\author{
${ }^{1}$ Azwarman, ${ }^{2}$ Susiana, ${ }^{3}$ Jodie Hidayah \\ ${ }^{1,2}$ Dosen Fakultas Teknik Universitas Batanghari Jambi \\ ${ }^{3}$ Mahasiswa Teknik Sipil Universitas Batanghari Jambi \\ warman2789@gmail.com
}

\begin{abstract}
ABSTRAK
Semakin padatnya Penduduk perkotaan maka sangat membutuhkan infrastruktur yang memadai untuk menunjang kehidupan masyarakat kota tersebut. Kepadatan pemukiman dan perkantoran serta pertokoan masalah banjir adalah sangat melekat pada kota perkotaan, dikarenakan berkurangnya daerah resapan yang disebabkan kepadatan bangunan di atas lahan yang seharusnya menjadi daerah resapan air sehingga bencana banjir tidak dapat dihindarkan. Kota Jambi terutama di daerah Kecamatan Alam Barajo yang merupakan pemekaran dari Kecamatan Kota Baru terdapat beberapa titik banjir yang diakibatkan minimnya drainase yang memadai dan terdapat perumahan yang seharusnya didaerah perumahan tersebut adalah daerah resapan air oleh karena itu penelitian ini diarahkan pada Kajian Drainase Ramah Lingkungan Dengan Memperhitungkan Sumur Resapan. Untuk mencegah banjir di lokasi penelitian yang padat akan penduduk dan perumahan yang jaraknya cukup rapat maka selain melakukan perawatan (maintenance) dan desain ulang drainase tersebut diperlukan juga sumur resapan agar debit air pada saat hujan tidak hanya ditampung oleh drainase tetapi juga oleh sumur resapan. Pada drainase drainase yang banyak terdapat semak - semak dan tertimbun oleh lumpur dan terdapat retak rambut pada dinding nya diadakan perbersihan dan perbaikan. Untuk desain ulang yaitu saluran primer maupun sekunder agar dapat menampung Karena dimanapun air akan tetap mengalir ke tempat yang lebih rendah dan jika aliran air tersebut penuh atau terhadang maka ia akan mencari aliran lain dengan cara mengalir ke jalan ataupun rumah warga. Dan hal ini dapat kita hindarkan dengan cara bersama - sama melakukan perencanaan dan perawatan yang baik untuk drainase aliran air tersebut.
\end{abstract}

Kata Kunci: Debit rencana ,Intensitas hujan,Sumur Resapan,type saluran drainase ,Kepadatan Penduduk

\section{PENDAHULUAN}

Pesatnya pertambahan penduduk kota Jambi tidak berbanding lurus dengan perkembangan infrastrukturnya sehingga mengakibatkan semakin berkurangnya daerah resapan air hujan. Banyak lahan yang seharusnya menjadi daerah resapan air hujan berubah fungsi menjadi pusat pertokoan, perumahan, dan ruko. Sehingga jika terjadi hujan dengan intensitas yang sangat tinggi air pun meluap ke permukaan jalan atau banjir. Untuk itu diperlukan saluran drainase maupun sumur resapan yang mampu untuk menampung atau mengalirkan debit air hujan ke tempat pembuangan akhir atau sungai, agar bencana banjir dapat dihindari, sehingga tidak terjadi banjir yang mengganggu fasilitas umum dan aktivitas masyarakat setempat. Selain untuk menampung air hujan, drainase juga berfungsi sebagai sarana untuk menyalurkan limbah rumah tangga maupun limbah pabrik, sistem ini mempunyai peranan yang sangat penting dalam menciptakan lingkungan sehat apalagi di daerah berpenduduk yang padat pada kota kota besar di Indonesia terutama Kota Jambi. Untuk sistem drainase terdapat sistem drainase konvensional dan sistem drainase ramah lingkungan. Di daerah padat penduduk seperti perumahan sistem konvensional tidak cocok untuk daerah tersebut, sistem drainase ramah lingkungan yang cocok untuk daerah padat penduduk. Selain dapat menghemat lahan, air hujan yang turun ditampung pada sistem drainase ramah lingkungan ini dapat digunakan untuk cadangan air pada musim kemarau. Sedangkan untuk sumur resapan berfungsi untuk menampung air hujan agar meresap ke dalam tanah agar tidak terjadi banjir, melindungi dan memperbaiki kualitas air tanah dan untuk menghindari terjadinya erosi. Drainase merupakan fasilitas dasar yang dirancang sebagai suatu sistem guna memenuhi kebutuhan masyarakat dan merupakan komponen penting dalam perencanaan suatu kota. Sama hal nya dengan drainase, sumur resapan juga mempunyai peran penting dalam suatu kawasan perkotaan. Secara umum drainase didefinisikan sebagai serangkaian bangunan air yang berfungsi untuk mengurangi dan membuang kelebihan air dari suatu kawasan atau lahan sehingga dapat berfungsi secara optimal. 
Ditinjau dari prasarana drainase kota Jambi yang ada saat ini, khususnya di Perumahan Aura Bimantara Kampung Bugis Kec. Alam Barajo terdapat saluran drainase yang tidak mampu menampung debit air yang melewati saluran tersebut jika terjadi hujan deras dengan durasi yang cukup lama, ditambah lagi dengan kurang perawatan drainase tersebut sehingga air yang mengalir tidak lancar dan tidak adanya sumur resapan di daerah perumahan tersebut. Oleh karena itu harus ada sistem drainase yang bagus serta ramah lingkungan dan sumur resapan yang memadai sehingga dapat mengontrol aliran air tersebut.

Dari uraian pada latar belakang, didapat permasalahan sebagai berikut yaitu terjadinya banjir pada Perumahan Aura Bimantara Kampung Bugis Kecamatan Alam Barajo Kota Jambi pada saat curah hujan tinggi dengan intensitas dan durasi yang cukup lama (kurang lebih 2 jam) dan apakah dimensi saluran yang ada mampu mengalirkan debit aliran air maksimum pada musim hujan.

Atas latar belakang dan rumusan masalah di atas maka penulis membatasi masalah yaitu, dimensi saluran, kecepatan dan debit air yang terdapat pada Perumahan Aura Bimantara Kampung Bugis Kec.Alam Barajo, data curah hujan yang didapat dari stasiun BMKG Sultan Thaha Kota Jambi dengan durasi 10 tahun yaitu tahun 2006 - 2015, peta Kota Jambi dan peta kontur Kota Jambi yang didapat dari Pemerintah Kota Jambi dan Catchment Area ( Daerah tangkapan air) adalah 0,216 km².

Tujuan yang hendak dicapai dalam penelitian ini adalah untuk mencari solusi dari penyebab terjadinya bencana banjir pada Perumahan Aura Bimantara Kampung Bugis Kec. Alam Barajo Kota Jambi, menentukan dimensi saluran yang mampu mengalirkan debit aliran air maksimum dan menentukan dimensi sumur resapan yang dapat menampung debit air berlebih.

Drainase yang berasal dari bahasa inggris drainage mempunyai arti mengalirkan, menguras, membuang, atau mengalihkan air.Dalam bidang teknik sipil, drainase secara umum dapat didefinisikan sebagai suatu tindakan teknis untuk mengurangi kelebihan air, baik yang berasal dari air hujan, rembesan, maupun kelebihan air irigasi dari suatu kawasan/lahan, sehingga fungsi kawasan tidak terganggu.(Suripin:2004)

Sedangkan sumur resapan merupakan sumur atau lubang pada permukaan tanah yang dibuat untuk menampung air hujan agar dapat meresap kedalam tanah. (Kusnaedi, $2011: 6$ ).

Konsep dasar sumur resapan pada hakekatnya adalah member kesempatan dan jalan pada air hujan yang jatuh di atap atau lahan yang kedap air untuk meresap kedalam tanah dengan jalan menampung air tersebut pada suatu sistem resapan. (Suripin, $2004: 299$ ).

Masing - masing drainase dan sumur resapan memiliki fungsi yang sama walaupun dalam segi bentuk berbeda, yaitu berfungsi mengurangi aliran air di permukaan jalan. Akan tetapi kalau di drainase aliran air dialihkan ke tempat yang lebih rendah, sedangkan aliran air pada sumur resapan akan tersimpan didalam tanah dan dapat digunakan pada saat kekeringan melanda.

\section{Persyaratan Umum dan Teknis Sumur Resapan}

Persyaratan umum sumur resapan yang harus dipenuhi berdasarkan (SNI No. 03-2453-2002), antara lain sebagai berikut :

1. Sumur resapan air hujan ditempatkan pada lahan yang relatif datar.

2. Air yang masuk ke dalam sumur resapan adalah air hujan yang tidak tercemar

3. Penetapan sumur resapan air hujan harus mempertimbangkan keamanan bangunan sekitarnya.

4. Harus memperhatikan peraturan daerah setempat.

5. Hal - hal yang tidak memenuhi ketentuan ini harus disetujui instansi yang berwenang.

Persyaratan teknis yang harus dipenuhi : (SNI No. 03-2453-2002)

1. Kedalaman air tanah minimum $1,50 \mathrm{~m}$ pada musim hujan.

2. Jarak penempatan sumur resapan air hujan terhadap bangunan, dapat dilihat pada tabel dibawah ini : 
Tabel 1. Jarak Minimal Sumur Resapan Dengan Bangunan Lainnya

\begin{tabular}{|c|c|}
\hline Kondisi yang ada & Jarak Minimal dengan Sumur Resapan (m) \\
\hline Bangunan & 3 \\
\hline Batas Pemilikan & 1,5 \\
\hline Sumur Air Minum & 10,5 \\
\hline Aliran Air (Sungai) & 30,5 \\
\hline Pipa Air Minum & 3 \\
\hline Jalan & 1,5 \\
\hline Pohon Besar & 3 \\
\hline
\end{tabular}

Sumber: Diolah dari Contteral dan Norris dalam Kalbermatten. Ak,1969 Diambil dari Buku Kusnaedi, 2011:8

\section{METODE PENELITIAN}

Lokasi penelitian yakni Perumahan Aura Bimantara Kampung Bugis Kecamatan Alam Barajo dengan luas areal $0,216 \mathrm{~km}^{2}$.

Dari hasil survey pengamatan di lapangan dan juga berdasarkan hasil wawancara dengan masyarakat dan instansi setempat yang telah dilakukan didapat adalah :

1. Terjadi banjir di perumahan ini terutama pada elevasi yang rendah.

2. Dibeberapa bagian saluran drainase terdapat semak yang mengganggu aliran air.

3. Aliran air dari drainase yang besar ke drainase yang kecil, sehingga tidak dapat menampung debit air yang di alirkan dari drainase yang besar.

4. Masalah utama adalah drainase yang kecil harus diperbesar dan membuat sumur resapan untuk mengefesienkan ruang.

\section{Teknik Pengumpulan Data}

Teknik pengumpulan data adalah tahapan yang dilakukan penelitian secara berurutan selama berlangsung penelitian. Berikut adalah tahapan penelitian yang akan dilakukan:

1. Studi Literatur

Dilakukan untuk menambah wawasan yang luas bagi peneliti tentang objek yang diteliti.

2. Observasi Lapangan

Observasi lapangan yaitu melakukan peninjauan ke lokasi atau lapangan.

3. Data Primer

Data primer diperoleh dengan cara peninjauan langsung di lapangan.

4. Data Sekunder

Data sekunder adalah data yang didapat dengan cara menghubungi instansi - instansi yang terkait dengan objek penelitian. Seperti:

1) Data curah hujan

2) Peta kontur

3) Peta kecamatan

4) Buku jurnal, hasil penelitian yang serupa

5) Data tanah daerah tersebut

\section{HASIL DAN PEMBAHASAN}

\section{Perencanaan Drainase}

Data - data dalam perencanaan drainase yaitu:

1. Data Topografi

Data Topografi didapat dengan melakukan pengamatan dan pengukuran langsung di lapangan.

2. Data Hidrologi

Data hidrologi yaitu data curah hujan, yang pada penelitian ini data curah hujan diperoleh dari Badan Meteorologi, Klimatologi dan Geofisika (BMKG) Stasiun Klas 1 Sultan Thaha Jambi.

3. Data Penunjang

Adapun data lain yang diperlukan namun masih bersifat sekunder. 


\section{Perhitungan Curah Hujan dan Intensitasnya (Metode Gumbel)}

1. Perhitungan curah hujan pertahun metode Gumbel:

$\mathrm{Xi}=\frac{\text { Jumlah Curah Hujan }(\mathrm{mm})}{12 \text { Bulan }}$

$\mathrm{Xi} 2006=174,667 \mathrm{~mm}$

Untuk perhitungan tahun 2007 - 2015 tetap menggunakan rumus diatas.

2. Perhitungan curah hujan rencana metode Gumbel

Curah hujan tahun $2006-2010=\mathrm{Xi}(2006-2010)-\mathrm{X}^{-}$

Nilai Xi diambil dari perhitungan curah hujan pertahun sedangkan nilai dari $\mathrm{X}^{-}=\frac{\sum \mathrm{Xi}}{\mathrm{N}}$

Tahun $2006=\left(X i 2006-X^{-} 2006\right)^{2}$

Tahun $2006=123,429 \mathrm{~mm}$

Untuk perhitungan tahun 2007 - 2015 tetap menggunakan rumus diatas.

$\sum \mathrm{Xi}=1857,765 \quad \sum(\mathrm{Xi}-\overline{\mathrm{X}})^{2}=9819,368$

$\overline{\mathrm{X}}=\frac{\sum \mathrm{Xi}}{\mathrm{N}}=\frac{1857,765}{10}=185,777 \quad \mathrm{~N}=10$

3. Perhitungan curah hujan rencana periode ulang $(\mathrm{T})$

$S=\sqrt{\frac{\sum(\mathrm{Xi}-\overline{\mathrm{X}})^{2}}{\mathrm{~N}-1}}=\sqrt{\frac{\mathbf{9 8 1 9 , 3 6 8}}{10-1}}=33,031, \quad \mathrm{X}_{\mathrm{Tr}}=\overline{\mathrm{X}}+\frac{\mathrm{Y}_{\mathrm{Tr}}-\mathrm{Y}_{\mathrm{n}}}{\mathrm{S}_{\mathrm{n}}} * \mathrm{~S}$

Tabel 2. Perhitungan Curah Hujan Rencana Periode Ulang (T)

\begin{tabular}{crlrrrrr}
\hline PeriodeUlang & \multicolumn{1}{l}{ YTr } & \multicolumn{1}{l}{ Yn } & \multicolumn{1}{l}{ Sn } & $X$ & XTr (mm) & P60 (T) mm/menit & StandarDeviasi (S) \\
\hline 2 & 0,3668 & 0,4952 & 0,9496 & 185,777 & 181,310 & 51,022 & 33,031 \\
5 & 1,5004 & 0,4952 & 0,9496 & 185,777 & 220,741 & 62,118 & 33,031 \\
10 & 2,251 & 0,4952 & 0,9496 & 185,777 & 246,850 & 78,748 & 33,031 \\
25 & 3,1993 & 0,4952 & 0,9496 & 185,777 & 279,836 & 85,634 & 33,031 \\
50 & 3,9028 & 0,4952 & 0,9496 & 185,777 & 304,307 & 92,470 & 33,031 \\
100 & 4,6012 & 0,4952 & 0,9496 & 185,777 & 328,600 & & \\
\hline
\end{tabular}

Sumber : Hasil Perhitungan 2017

4. Perhitungan hasil analisis frekuensi

$\mathrm{Pi}=(0,21 \cdot \operatorname{Ln}(\mathrm{T})+0,52) \times\left(0,54 . \mathrm{t}^{0,25}-0,50\right) \times\left[\frac{\mathrm{P}^{60 \times 60}}{\mathrm{t}}\right]$

Periode ulang 2 durasi $5-120$ menit

$\mathrm{Pi}=(0,21 \cdot \operatorname{Ln}(2)+0,52) \times\left(0,54 \cdot(5)^{0,25}-0,50\right) \times\left[\frac{51,022 * 60}{5}\right]=\mathrm{Pi}=125,301 \mathrm{~mm} / \mathrm{menit}$

Tabel 3. Hasil Analisis Frekuensi

\begin{tabular}{|c|c|c|c|c|c|c|}
\hline \multirow[b]{2}{*}{ Durasi (Menit) } & \multicolumn{5}{|c|}{ PeriodeUlang (mm/menit) } & \multirow[b]{2}{*}{100} \\
\hline & 2 & 5 & 10 & 25 & 50 & \\
\hline 5 & 125,301 & 196,656 & 257,226 & 347,509 & 423,892 & 507,397 \\
\hline 10 & 93,780 & 147,184 & 192,517 & 260,089 & 317,256 & 379,754 \\
\hline 20 & 65,400 & 102,642 & 134,256 & 181,379 & 221,246 & 264,831 \\
\hline 30 & 51,874 & 81,414 & 106,490 & 143,866 & 175,488 & 210,059 \\
\hline 40 & 43,706 & 68,595 & 89,722 & 121,213 & 147,856 & 176,983 \\
\hline 60 & 34,057 & 53,451 & 69,914 & 94,453 & 115,214 & 137,911 \\
\hline 80 & 28,397 & 44,568 & 58,295 & 78,756 & 96,067 & 114,991 \\
\hline 120 & 21,857 & 34,303 & 44,869 & 60,617 & 73,941 & 88,507 \\
\hline
\end{tabular}

Sumber : Hasil Perhitungan 2017 
Kajian Drainase Ramah Lingkungan dengan Memperhitungkan Sumur Resapanuntuk Antisipasi Banjï pada Perumahan Aura Bimantara Kampung Bugis Kecamatan Alam Barajo

Perhitungan Curah Hujan Rencana dengan Metode Log Person Tipe III

Tabel 4. Perhitungan Curah Hujan Rencana

\begin{tabular}{|c|c|c|c|c|c|c|c|c|c|}
\hline No. & Tahun & $\mathbf{X i}(\mathrm{mm})$ & $\log X \mathbf{X}$ & $\log X i-\log \bar{X}$ & $(\log X i-\log \bar{X})^{2}$ & $(\log X i-\log \bar{x})^{3}$ & $\mathbf{S}$ & $\mathbf{G}$ & $\log \bar{x}$ \\
\hline 1 & 2006 & 174,667 & 2,242 & $-0,021$ & 0,00045 & $-0,0000096$ & \multirow{11}{*}{0,07095} & \multirow{10}{*}{1,2022} & \multirow{10}{*}{2,263} \\
\hline 2 & 2007 & 185,500 & 2,268 & 0,005 & 0,00002 & 0,0000001 & & & \\
\hline 3 & 2008 & 185,583 & 2,269 & 0,005 & 0,00003 & 0,0000001 & & & \\
\hline 4 & 2009 & 191,500 & 2,282 & 0,019 & 0,00035 & 0,0000065 & & & \\
\hline 5 & 2010 & 267,250 & 2,427 & 0,163 & 0,02671 & 0,0043648 & & & \\
\hline 6 & 2011 & 192,083 & 2,283 & 0,020 & 0,00040 & 0,0000080 & & & \\
\hline 7 & 2012 & 160,833 & 2,206 & $-0,057$ & 0,00326 & $-0,0001863$ & & & \\
\hline 8 & 2013 & 195,667 & 2,292 & 0,028 & 0,00079 & 0,0000220 & & & \\
\hline 9 & 2014 & 148,500 & 2,172 & $-0,092$ & 0,00842 & $-0,0007727$ & & & \\
\hline \multirow[t]{2}{*}{10} & 2015 & 156,182 & 2,194 & $-0,070$ & 0,00488 & $-0,0003410$ & & & \\
\hline & & $\Sigma$ & 22,635 & & 0,04531 & 0,0030919 & & & \\
\hline
\end{tabular}

Sumber : Hasil Perhitungan 2017

Curah hujan rata - rata :

$\log \overline{\mathrm{x}}=\frac{\sum \log \mathrm{Xi}}{\mathrm{N}}=\frac{22,635}{10}=2,263$

Simpangan Baku :

$\mathrm{S}=\left\lceil\frac{\sum(\log \mathrm{x}-\log \overline{\mathrm{x}}}{\mathrm{N}-1}\right\rceil^{0,5}=\left\lceil\frac{0,04531}{10-1}\right\rceil^{0,5}=0,07095$

Hitung koefisien kemencengan :

$\mathrm{G}=\frac{\mathrm{N} \cdot \sum(\log \mathrm{x}-\log \overline{\mathrm{x}})^{3}}{(\mathrm{~N}-\mathrm{I})(\mathrm{N}-2) \mathrm{s}^{3}}=\mathrm{G}=1,2022$

Perhitungan Curah Hujan Rencana Periode Ulang (T) Metode Log Person Tipe III

Nilai KT didapat dari tabel 3.6a pada buku Teknik Perhitungan Debit Rencana Bangunan Air

(Kamiana, 2011:205).Sesuai nilai $\mathrm{G}=1,2022$

$\log \mathrm{X}_{\mathrm{Tr}}(2$ tahun)

$\log \overline{\mathrm{X}}+\mathrm{K}_{\mathrm{T}} * \mathrm{~S}=2,263+(-0.195) * 0,07095=2,250$

JadiX $_{\mathrm{Tr}}(2$ tahun $)=10^{2,250}=177,486 \mathrm{~mm} /$ tahun

Tabel 5. Perhitungan Curah Hujan Rencana Periode Ulang (T)

\begin{tabular}{llll}
\hline PeriodeUlang & KT & Log $\mathbf{X T r}$ & $\mathbf{X T r}(\mathbf{m m})$ \\
\hline 2 & $-0,195$ & 2,250 & 177,486 \\
5 & 0,732 & 2,315 & 206,507 \\
10 & 1,34 & 2,359 & 228,073 \\
25 & 2,087 & 2,412 & 257,675 \\
50 & 2,626 & 2,450 & 281,394 \\
100 & 3,149 & 2,487 & 306,494 \\
\hline
\end{tabular}

Sumber : Hasil Perhitungan 2017

Tabel 6. Hasil Perhitungan Curah Hujan Dengan Dua Metode

\begin{tabular}{cccccccc}
\hline \multirow{2}{*}{ No. } & \multirow{2}{*}{ Metode } & $\mathbf{2}$ & $\mathbf{5}$ & $\mathbf{1 0}$ & $\mathbf{2 5}$ & $\mathbf{5 0}$ & $\mathbf{1 0 0}$ \\
\hline 1 & Gumbel & 181,31 & 220,741 & 246,85 & 279,836 & 304,307 & 328,6 \\
2 & Log Person Tipe III & 177,687 & 206,742 & 228,332 & 257,970 & 281,716 & 306,846 \\
\hline
\end{tabular}

Sumber : Hasil Perhitungan 2017

Untuk memilih curah hujan rencana yang akan digunakan. Berikut rumus nya dapat dilihat di bawah ini : 
Kajian Drainase Ramah Lingkungan dengan Memperhitungkan Sumur Resapanuntuk Antisipasi Banjir pada Perumahan Aura Bimantara Kampung Bugis Kecamatan Alam Barajo

1) Talbot

$$
\begin{aligned}
& \mathrm{a}=\frac{\sum(\mathrm{t} \mathrm{x}) \mathrm{x} \sum\left(\mathrm{I}^{2}\right)-\sum\left(\mathrm{I}^{2} \mathrm{xt}\right) \mathrm{x} \sum(\mathrm{I})}{\mathrm{N} \times \sum\left(\mathrm{i}^{2}\right)-\sum(\mathrm{I}) \mathrm{x}(\mathrm{I})} \\
& \mathrm{b}=\frac{\sum(\mathrm{I}) \mathrm{x} \sum(\mathrm{tx} \mathrm{I})-\mathrm{N} \times \sum\left(\mathrm{I}^{2} \mathrm{xt}\right)}{\mathrm{N} \times \sum\left(\mathrm{I}^{2}\right)-\sum(\mathrm{I}) \mathrm{x}(\mathrm{I})}
\end{aligned}
$$

2) Ishiguro

$$
\begin{aligned}
& \mathrm{a}=\frac{\sum(\mathrm{I} \sqrt{\mathrm{t}}) \times \sum\left(\mathrm{I}^{2}\right)-\sum\left(\mathrm{I}^{2} \mathrm{x} \sqrt{\mathrm{t}}\right) \times \sum(\mathrm{I})}{\mathrm{N} \times \sum\left(\mathrm{i}^{2}\right)-\sum(\mathrm{I}) \times(\mathrm{I})} \\
& \mathrm{b}=\frac{\sum(\mathrm{I}) \times \sum(\mathrm{I} \sqrt{\mathrm{t}})-\mathrm{N} \sum\left(\mathrm{I}^{2} \times \sqrt{\mathrm{t}}\right)}{\mathrm{N} \times \sum\left(\mathrm{I}^{2}\right)-\sum(\mathrm{I}) \times(\mathrm{I})}
\end{aligned}
$$

3) Sherman

$$
\begin{aligned}
\log \mathrm{a} & =\frac{\sum(\log \mathrm{I}) \mathrm{x} \sum(\log \mathrm{t})^{2}-\sum(\log \mathrm{t} \mathrm{x} \log \mathrm{I}) \mathrm{x} \sum(\log \mathrm{t})}{\mathrm{N} \times \sum(\log \mathrm{t})^{2}-\sum(\log \mathrm{t}) \mathrm{x}(\log \mathrm{t})} \\
\mathrm{n} & =\frac{\sum(\log \mathrm{I}) \mathrm{x} \sum(\log \mathrm{t})-\mathrm{N} \mathrm{x} \sum(\log \mathrm{x} \log \mathrm{I})}{\mathrm{N} \mathrm{x} \sum(\log \mathrm{t})^{2}-\sum(\log \mathrm{t}) \mathrm{x}(\log \mathrm{t})}
\end{aligned}
$$

Berikut tabel yang digunakan untuk sebagai data masukkan dalam perhitungan tetapan rumus Talbot,

\begin{tabular}{|c|c|c|c|c|c|c|c|}
\hline PeriodeUlang $(\mathbf{T})$ & $\begin{array}{l}\text { Talbot } \\
\text { a }\end{array}$ & b & $\begin{array}{l}\text { Ishiguro } \\
\text { a }\end{array}$ & b & $\begin{array}{l}\text { Sherman } \\
\text { Log a }\end{array}$ & $\mathbf{a}$ & $\mathbf{N}$ \\
\hline 2 & 2691,948 & 18,134 & 251,433 & $-0,378$ & 2,517 & 328,496 & 0,555 \\
\hline 5 & 4224,919 & 18,134 & 394,616 & $-0,378$ & 2,829 & 674,357 & 0,555 \\
\hline 10 & 5526,193 & 18,134 & 516,157 & $-0,378$ & 2,829 & 674,357 & 0,555 \\
\hline 25 & 7465,830 & 18,134 & 697,323 & $-0,378$ & 2,960 & 911,049 & 0,555 \\
\hline 50 & 9106,814 & 18,134 & 850,594 & $-0,378$ & 3,046 & 1111,297 & 0,555 \\
\hline 100 & 10900,832 & 18,134 & 1018,159 & $-0,378$ & 3,124 & 1330,220 & 0,555 \\
\hline
\end{tabular}
Ishiguro dan Sherman (sebagai contoh periode ulang 2 tahun)

\begin{tabular}{cccccccccccc}
\hline $\mathbf{t}$ & $\mathbf{I}$ & $\mathbf{L o g} \mathbf{t}$ & $\mathbf{L o g} \mathbf{I}$ & $\begin{array}{c}\mathbf{L o g} \mathbf{~} \mathbf{x} \\
\mathbf{L o g} \mathbf{I}\end{array}$ & $\mathbf{( L o g} \mathbf{t})^{\mathbf{2}}$ & $\mathbf{t} \mathbf{x} \mathbf{I}$ & $\mathbf{I}^{\mathbf{2}}$ & $\mathbf{t}_{\mathbf{x}} \mathbf{I}^{2}$ & $\sqrt{\mathbf{t}}$ & $\mathbf{I} \mathbf{x} \sqrt{\mathbf{t}}$ & $\mathbf{I}^{\mathbf{2}} \mathbf{x} \sqrt{\mathbf{t}}$ \\
\hline 5 & 125,301 & 0,699 & 2,098 & 1,466 & 0,489 & 626,506 & 15700,374 & 78501,872 & 2,236 & 280,182 & 35107,105 \\
10 & 93,780 & 1,000 & 1,972 & 1,972 & 1,000 & 937,799 & 8794,673 & 87946,733 & 3,162 & 296,558 & 27811,199 \\
20 & 65,400 & 1,301 & 1,816 & 2,362 & 1,693 & 1307,992 & 4277,105 & 85542,110 & 4,472 & 292,476 & 19127,797 \\
30 & 51,874 & 1,477 & 1,715 & 2,533 & 2,182 & 1556,213 & 2690,886 & 80726,590 & 5,477 & 284,124 & 14738,591 \\
40 & 43,706 & 1,602 & 1,641 & 2,628 & 2,567 & 1748,227 & 1910,186 & 76407,457 & 6,325 & 276,419 & 12081,080 \\
60 & 34,057 & 1,778 & 1,532 & 2,724 & 3,162 & 2043,413 & 1159,872 & 69592,299 & 7,746 & 263,804 & 8984,327 \\
80 & 28,397 & 1,903 & 1,453 & 2,766 & 3,622 & 2271,758 & 806,388 & 64511,077 & 8,944 & 253,990 & 7212,558 \\
120 & 21,857 & 2,079 & 1,340 & 2,785 & 4,323 & 2622,796 & 477,712 & 57325,483 & 10,954 & 239,427 & 5233,077 \\
Jumlah & $\mathbf{4 6 4 , 3 7 1}$ & $\mathbf{1 1 , 8 4 0}$ & $\mathbf{1 3 , 5 6 6}$ & $\mathbf{1 9 , 2 3 7}$ & $\mathbf{1 9 , 0 3 6}$ & $\mathbf{1 3 1 1 4 , 7 0 4}$ & $\mathbf{3 5 8 1 7 , 1 9 9}$ & $\mathbf{6 0 0 5 5 3 , 6 2 1}$ & $\mathbf{4 9 , 3 1 7}$ & $\mathbf{2 1 8 6 , 9 8 0}$ & $\mathbf{1 3 0 2 9 5 , 7 3 4}$ \\
\hline
\end{tabular}

Untuk Periode Ulang 5,10,25,50 dan 100 tahun rumus tetap sama dengan yang diatas sehingga hasilnya langsung ditabelkan seperti dibawah

Tabel 7. Hasil Perhitungan Konstanta Lamanya Hujan (A,B,N)

Sumber : Hasil Perhitungan 2017

\section{Analisa Aliran}

Untuk menentukan limpasan (run off) dibutuhkan data intensitas curah hujan dalam jangka pendek dengan durasi 5 sampai 120 menit.Berikut langkah mencari intensitas curah hujan jangka pendek di bawah ini.

Perhitungan intensitas durasi metode Talbot periode ulang 2 tahun dengan durasi 5 menit. Untuk nilai $\mathrm{a}, \mathrm{t}$, dan $\mathrm{b}$ diambil dari tabel hasil perhitungan konstanta lamanya hujan diatas.
I 2 tahun $=\frac{a}{t+b}$
I 5 tahun $=\frac{a}{t+b}$

Untuk perhitungan selanjutnya tinggal mengganti nilai t (durasi menit) dan tetap menggunakan rumus diatas. 
Tabel 8. Perhitungan Intensitas Durasi Metode Talbot

\begin{tabular}{|c|c|c|c|c|c|c|c|}
\hline \multirow[t]{2}{*}{ No. } & \multirow[t]{2}{*}{ Durasi (menit) } & \multicolumn{6}{|c|}{$\begin{array}{c}\text { Intensitas (mm/menit) } \\
\text { Return Period }\end{array}$} \\
\hline & & 2 Tahun & 5 Tahun & 10 Tahun & 25 Tahun & 50 Tahun & 100 Tahun \\
\hline 1 & 5 & 116,363 & 182,628 & 238,878 & 322,722 & 393,656 & 471,205 \\
\hline 2 & 10 & 95,683 & 150,172 & 196,424 & 265,367 & 323,695 & 387,462 \\
\hline 3 & 20 & 70,592 & 110,792 & 144,915 & 195,779 & 238,811 & 285,856 \\
\hline 4 & 30 & 55,926 & 87,774 & 114,809 & 155,105 & 189,197 & 226,469 \\
\hline 5 & 40 & 46,306 & 72,676 & 95,060 & 128,425 & 156,652 & 187,512 \\
\hline 6 & 60 & 34,453 & 54,073 & $\mathbf{7 0 , 7 2 7}$ & 95,552 & 116,554 & 139,515 \\
\hline 7 & 80 & 27,431 & 43,053 & 56,313 & 76,078 & 92,800 & 111,081 \\
\hline 8 & 120 & 19,488 & 30,586 & 40,006 & 54,048 & 65,927 & 78,915 \\
\hline
\end{tabular}

Sumber : Hasil Perhitungan 2017

Perhitungan intensitas durasi metode ishiguro periode 2 tahun dengan durasi 5 menit.Untuk nilai $\mathrm{a}, \sqrt{\mathrm{t}}$, dan b diambil dari table perhitungan konstanta lamanya hujan.
I 2 tahun $=\frac{a}{\sqrt{t}+b}$
I5tahun $=\frac{a}{\sqrt{t}+b}$

Untuk perhitungan selanjutnya tinggal mengganti nilai $t$ (durasi menit) dan tetap menggunakan rumus diatas.

Tabel 9. Hasil Dari Perhitungan Intensitas Durasi Metode Ishiguro

\begin{tabular}{|c|c|c|c|c|c|c|c|}
\hline \multirow[t]{2}{*}{ No } & \multirow[t]{2}{*}{ Durasi (menit) } & \multicolumn{6}{|c|}{$\begin{array}{c}\text { Intensitas (mm/menit) } \\
\text { Return Period }\end{array}$} \\
\hline & & 2Tahun & 5Tahun & 10Tahun & 25Tahun & 50Tahun & 100 Tahun \\
\hline 1 & 5 & 135,317 & 212,375 & 277,787 & 375,287 & 457,775 & 547,955 \\
\hline 2 & 10 & 90,303 & 141,728 & 185,380 & 250,447 & 305,495 & 365,677 \\
\hline 3 & 20 & 61,412 & 96,385 & 126,071 & 170,321 & 207,757 & 248,685 \\
\hline 4 & 30 & 49,308 & 77,387 & 101,222 & 136,750 & 166,807 & 199,668 \\
\hline 5 & 40 & 42,282 & 66,360 & 86,799 & 117,264 & 143,039 & 171,217 \\
\hline 6 & 60 & 34,125 & 53,558 & 70,054 & 94,642 & 115,444 & 138,187 \\
\hline 7 & 80 & 29,351 & 46,066 & 60,254 & 81,403 & 99,295 & 118,856 \\
\hline 8 & 120 & 23,773 & 37,311 & 48,802 & 65,931 & 80,423 & 96,266 \\
\hline
\end{tabular}

Sumber : Hasil Perhitungan 2017

Perhitungan intensitas durasi metode Sherman periode ulang 2 tahun dengan durasi 5 menit. Untuk nilai a, $\mathrm{t}^{\mathrm{n}}$, diambil dari tabel perhitungan konstanta lamanya hujan.

I 2 tahun $=\frac{\mathrm{a}}{\mathrm{t}^{\mathrm{n}}} \quad, \quad$ I5 tahun $=\frac{\mathrm{a}}{\mathrm{t}^{\mathrm{n}}}$

Untuk perhitungan selanjutnya tinggal mengganti nilai $t$ (durasi menit) dan tetap menggunakan rumus diatas.

Tabel 10. Perhitungan Intensitas Durasi Metode Sherman

\begin{tabular}{|c|c|c|c|c|c|c|c|}
\hline \multirow[t]{2}{*}{ No. } & \multirow[t]{2}{*}{ Durasi (menit) } & \multicolumn{6}{|c|}{$\begin{array}{c}\text { Intensitas (mm/menit) } \\
\text { Return Period }\end{array}$} \\
\hline & & 2 Tahun & 5 Tahun & 10 Tahun & 25 Tahun & 50 Tahun & 100 Tahun \\
\hline 1 & 5 & 134,553 & 276,218 & 276,218 & 373,168 & 455,190 & 544,861 \\
\hline 2 & 10 & 91,611 & 188,064 & 188,064 & 254,072 & 309,917 & 370,970 \\
\hline 3 & 20 & 62,373 & 128,044 & 128,044 & 172,986 & 211,008 & 252,576 \\
\hline 4 & 30 & 49,813 & 102,259 & 102,259 & 138,151 & 168,516 & 201,714 \\
\hline 5 & 40 & 42,467 & 87,179 & 87,179 & 117,778 & 143,666 & 171,967 \\
\hline 6 & 60 & 33,915 & 69,623 & 69,623 & 94,061 & 114,735 & 137,337 \\
\hline 7 & 80 & 28,914 & 59,356 & 59,356 & 80,190 & 97,815 & 117,085 \\
\hline 8 & 120 & 23,091 & 47,403 & 47,403 & 64,041 & 78,118 & 93,507 \\
\hline
\end{tabular}


Tabel 11. Hasil Perhitungan Intensitas Durasi Tiga Metode Periode Ulang 10 Tahun

\begin{tabular}{ccccc}
\hline No. & Durasi (menit) & Talbot & $\begin{array}{c}\text { Metode } \\
\text { Ishiguro } \\
\text { 10 Tahun }\end{array}$ & Sherman \\
\hline 1 & 5 & 238,878 & 277,787 & 276,218 \\
2 & 10 & 196,424 & 185,380 & 188,064 \\
3 & 20 & 144,915 & 126,071 & 128,044 \\
4 & 30 & 114,809 & 101,222 & 102,259 \\
5 & 40 & 95,060 & 86,799 & 87,179 \\
6 & 60 & $\mathbf{7 0 , 7 2 7}$ & $\mathbf{7 0 , 0 5 4}$ & $\mathbf{6 9 , 6 2 3}$ \\
7 & 80 & 56,313 & 60,254 & 59,356 \\
8 & 120 & 40,006 & 48,802 & 47,403 \\
\hline
\end{tabular}

Sumber : Hasil perhitungan 2017

Setelah mendapatkan intensitas hujan maka kita akan mencari debit rencana dimana disini menggunakan metode rasional dikarenakan luas area kurang dari $300 \mathrm{Ha}$. Rumus metode ini yaitu :

$Q_{T}=0,278 * C * C_{s} * I * A$

Di mana:

$\mathrm{Q}_{\mathrm{T}} \quad=$ Debit rencana $\left(\mathrm{m}^{3} / \mathrm{det}\right)$

$\mathrm{C} \quad=$ Koefisien pengaliran

Cs $\quad=$ Koefisien tampungan

I $\quad=$ Intensitas hujan $(\mathrm{mm} / \mathrm{menit})$

A $\quad=$ Luas daerah tangkapan hujan $\left(\mathrm{km}^{2}\right)$

Nilai C (koefisien pengaliran) didapat dari tabel Wesli halaman 32. Dikarenakan perumahan yang ditinjau kerapatan nya sedang, koefisien yang diambil $0,40-0,70$. Berikut rumus yang digunakan dalam perhitungan koefisien tampungan. (Wesli, $2008: 33$ ).

$C s=\frac{2 T c}{2 T c+T d}$

Di mana:

Cs $\quad=$ Koefisien tampungan

Tc $\quad=$ Waktu konsentrasi (jam)

$\mathrm{Td}=$ Conduit time sampai ketempat pengukuran (jam)

$C s=\frac{2 * 0,642}{(2 * 0,642)+0,025}=0,981$

Nilai I (Intensitas hujan) didapat dari perhitungan diatas dan yang digunakan adalah angka dari metode Talbot yaitu 70,727 mm/menit. Nilai A (Luas daerah tangkapan hujan) yaitu 0,216 km2 atau 21,6 hektar.

Didapat luas total sebesar $215681,17 \mathrm{~m}^{2}=0,216 \mathrm{~km}^{2}$

Sehingga nilai A yang digunakan adalah $0,216 \mathrm{~km}^{2}$

Perhitungan debit rencana :

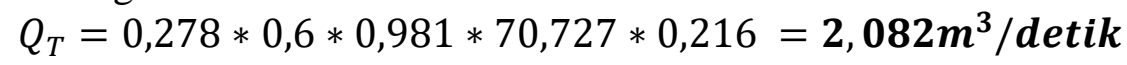

Perhitungan rencana dimensi saluran drainase :

Perhitungan saluran drainase menggunakan debit rencana $\left(\mathrm{Q}_{\mathrm{T}}\right)$, berikut perhitungan dimensi saluran drainase di Kelurahan Kenali Besar Kecamatan Alam Barajo Kota Jambi:

a. Mencari luas penampang saluran

$$
A_{S}=\frac{Q_{T}}{V_{\text {Perhitungan }}}=\frac{2,082 \mathrm{~m}^{3} / \mathrm{d}}{2,508 \mathrm{~m} / \mathrm{d}}=\mathbf{0 , 8 3 0} \mathbf{m}^{2}
$$

b. Mencari tinggi saluran

$\mathrm{H}=\sqrt{\mathrm{As}}, \mathrm{H}=\sqrt{0,776}=0,911 \mathrm{~m}$, Dipakai tinggi awal 1,4 $\mathrm{m}$

c. Mencari lebar saluran

$\mathrm{B}=\sqrt{\mathrm{As}}, \mathrm{B}=\sqrt{0,776}=0,911 \mathrm{~m}$, Dipakailebarawal $1,4 \mathrm{~m}$ 
d. Mencari keliling basah saluran

$\mathrm{Ps}=\mathrm{B}+2 \mathrm{H}, \mathrm{Ps}=1,4+2 \times 1,4=4,2 \mathrm{~m}$

e. Mencari Jari - jari Hidraulis

$\mathrm{Rs}=\frac{\mathrm{As}}{\mathrm{Ps}}, \mathrm{Rs}=\frac{1,960}{4,2}=0,467 \mathrm{~m}$

f. Mencari Tinggi Jagaan

$\mathrm{F}=10 \% \mathrm{H}, \mathrm{F}=0,1 \times 1,4=0,14 \mathrm{~m}$

g. Mencari Debit Kontrol

$\mathrm{Qs}=\mathrm{As} \cdot \frac{1}{\mathrm{n}} \cdot \mathrm{R}^{\frac{2}{3}} \cdot \mathrm{s}^{\frac{1}{2}}$

Qs $=0,830 \cdot \frac{1}{0,022} \cdot 0,467^{\frac{2}{3}} \cdot 0,0086^{\frac{1}{2}}$

Qs = 2,082 $\mathrm{m}^{3} /$ detik $\geq Q_{\mathrm{T}}=\mathbf{2 , 0 8 2} \mathrm{m}^{3} /$ detik

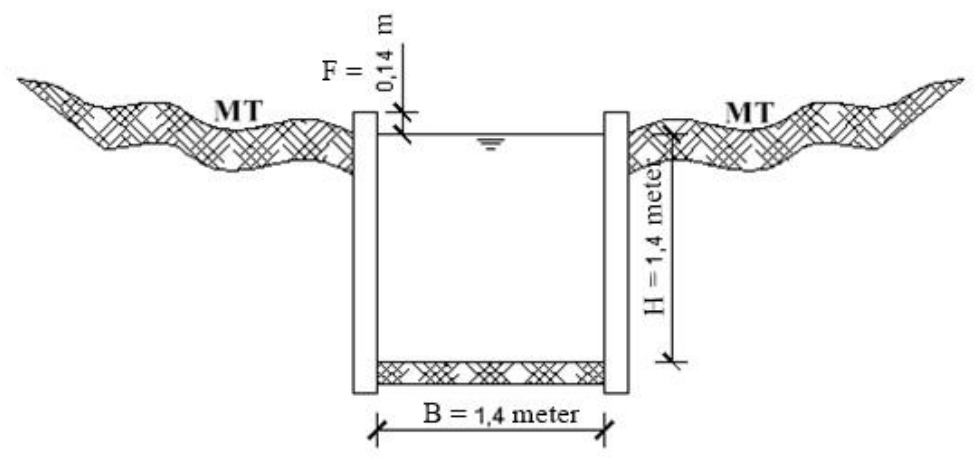

Gambar 1. Rencana Dimensi Saluran Drainase

\section{Perencanaan Sumur Resapan}

Hal pertama untuk merencanakan sumur resapan adalah dengan mencari nilai permeabilitas tanah (K). Dalam hal ini penulis langsung ke lokasi untuk mengambil sampel tanah dan diuji di Laboratorium Fakultas Teknik Universitas Batanghari dan didapat hasil nilai permeabilitas tanah untuk jenis tanah lanau sebesar : $4,5 \times 10^{-3} \mathrm{~cm} /$ detik. Direncanakan sumur resapan berbentuk bulat dengan dimensi diameter $=1,5$ meter, Jari - jari sumur $=0,75$ meter dan kedalaman sumur $=2$ meter.

Dan berikut adalah perhitungan sumur resapan untuk masalah ini :

1) Faktor Geometrik

$\mathrm{F}_{1}=5,5 \cdot \mathrm{R}_{1}$

$\mathrm{F}_{1}=5,5 \times 0,75=4,125 \mathrm{~m}$

2) Waktu Pengaliran (T)

$\mathrm{T}=1 \times 60 \times 60=3600$ detik

3) Koefisien Permaebilitas Tanah (k)

$\mathrm{K}=4,5 \times 10^{-3}(\mathrm{~cm} /$ detik $)=4,5 \times 10^{-5}(\mathrm{~m} /$ detik $)$

4) Kapasitas Sumur Resapan

$\mathrm{V}_{\text {sumur }}=\frac{1}{4} \cdot \pi \cdot \mathrm{D}^{2} \cdot \mathrm{H}=\mathrm{V}_{\text {sumur }}=\frac{1}{4} \cdot 3,14 \cdot 1,5^{2} \cdot 2=3,533 \mathrm{~m}^{3}$

5) Menghitung debit resap sumur resapan

$\mathrm{Q}_{\text {resap }}=\mathrm{F}_{1} \cdot \mathrm{K} \cdot \mathrm{H}_{1}=4,125 \times 4,5 \times 10^{-5} \times 2=0,000371 \mathrm{~m}^{3} / \mathrm{detik}$

6) Waktu Resap Air

$\mathrm{T}_{\text {resap }}=\frac{\mathrm{V}_{\text {Sumur }}}{\mathrm{Q}_{\text {resap }}}=\frac{3,533}{0,000371}=9515,152 \mathrm{detik}=158,586$ menit $=2,643 \mathrm{jam}$.

7) Menghitung $Q$ dari atap yang turun ke sumur resapan

$Q_{\text {atap }}=0,278 \times \mathrm{C} \times \mathrm{I} \times \mathrm{A}=0,278 \times 0.9 \times 70,727 \times 0,108=1,924 \mathrm{~m}^{3} /$ detik

8) Menghitung volume air akibat limpasan

$\mathrm{V}_{1}=$ Qlimpasan. $\mathrm{T}=(\mathrm{Qt}-\mathrm{Q}$ atap $)$ x $\mathrm{T}=(2,802-1,924) \times 3600=3160,8 \mathrm{~m}^{3}$

9) Menghitung jumlah sumur yang dibutuhkan, untuk mengabiskan limpasan/banjir. 
$\mathrm{JS}=\frac{\mathrm{V}_{1}}{\mathrm{~V}_{\text {sumur }}}=\frac{3160,8}{3,533}=894,7$ sumur $=895$ buah sumur resapan

10) Menghitung pengurangan debit air dengan adanya sumur resapan

$Q_{\text {pengurangan }}=Q_{T}-Q_{\text {atap }}=2,802-1,924=0,878 \mathrm{~m}^{3} /$ detik

Jadi persentase pengurangan debit air nya adalah sebagai berikut :

$Q_{\%}=\frac{Q_{\text {pengurangan }}}{Q_{t}} \times 100 \%=\frac{0,878}{2,802} \times 100 \%=31,33 \%$

pengurangan dari debit yang ada sebelum adanya sumur resapan

\section{SIMPULAN}

Berdasarkan hasil dari tinjauan pada bab sebelumnya didapat kesimpulan sebagai berikut:

1. Dari data curah hujan selama 10 tahun (2006 - 2015), didapat intensitas hujan dengan durasi 60 menit sebesar $=70,727 \mathrm{~mm} / \mathrm{jam}$.

2. Dari perhitungan didapatlah debit rencana sebesar $=2,457 \mathrm{~m}^{3} /$ detik

3. Drainase ramah lingkungan dapat dibuat di daerah tersebut dengan catatan sumur resapan harus dibuat sesuai dengan fungsinya.

4. Dimensi penampang yang dapat menyalurkan debit maksimum sebesar $2,082 \mathrm{~m}^{3} / \mathrm{detik}$ berbentuk persegi empat, dengan lebar saluran $(B)=1,4$ meter, tinggi saluran $(H)=1,4$ meter, tinggi jagaan $(F)=0,14$.

5. Desain sumur resapan yang telah dihitung sesuai untuk daerah tersebut dengan diameter sumur $=1,5$ meter dengan kedalaman sumur=3,652meter.

\section{DAFTAR PUSTAKA}

"Pola Jaringan Drainase" http://architulistiwa.blogspot.co.id/2014/11/definisi-fungsi-dan-macam-macamdrainase_27.html diakses 30 Desember 2016

Badan Meteorologi Klimatologi dan Geofisika, (BMKG) Sultan Thaha Kota Jambi.

Fauzi Dimitri. 2015. Jurnal Analisis dan Evaluasi Saluran Drainase pada Kawasan Perumnas Talang Kelapa di Subdas Lambidaro Kota Palembang.Architulistiwa. (2014),

Kusnaedi, 2011. Sumur Resapan Untuk Pemukiman Perkotaan dan Pedesaan.

Kusuma Satria. 2017. Tinjauan Drainase Kelurahan Budiman Kecamatan Jambi Timur

Mulyanto, H.,R., 2013. Penataan Drainase Perkotaan, Edisi Pertama- Yogyakarta : Graha Ilmu.

Sanjaya Desra Mulki. 2014 . Perencanaan Drainase dengan Sistem Jaringan dan Sumur Resapan Kelurahan Simpang IV Sipin Kecamatan Telanaipura Kota Jambi.

Suripin. 2004. Sistem Drainase Perkotaan yang Berkelanjutan, Edisi Pertama - Andi Yogyakarta.

Wesli. 2008. Drainase Perkotaan, Edisi Pertama - Yogyakarta; Graha Ilmu.TN Sipil. (2016),

Wikipedia. (2016),’Pengertian Drainase.” https://id.wikipedia.org/wiki/Drainase diakses 24 Desember 2016 